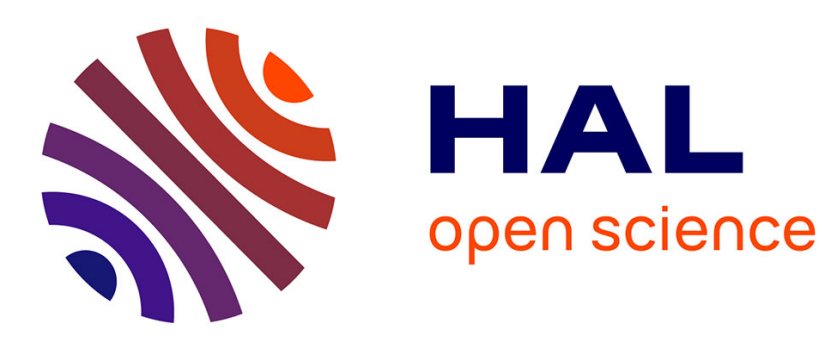

\title{
Color Constrained ICP for Registration of Large Unstructured 3D/color Data Sets
}

Sébastien Druon, Marie-José Aldon, André Crosnier

\section{To cite this version:}

Sébastien Druon, Marie-José Aldon, André Crosnier. Color Constrained ICP for Registration of Large Unstructured 3D/color Data Sets. IEEE ICIA'06: International Conference on Information Acquisition, Aug 2006, pp.249-255. lirmm-00128684

\section{HAL Id: lirmm-00128684 https://hal-lirmm.ccsd.cnrs.fr/lirmm-00128684}

Submitted on 2 Feb 2007

HAL is a multi-disciplinary open access archive for the deposit and dissemination of scientific research documents, whether they are published or not. The documents may come from teaching and research institutions in France or abroad, or from public or private research centers.
L'archive ouverte pluridisciplinaire HAL, est destinée au dépôt et à la diffusion de documents scientifiques de niveau recherche, publiés ou non, émanant des établissements d'enseignement et de recherche français ou étrangers, des laboratoires publics ou privés. 


\title{
Color Constrained ICP for Registration of Large Unstructured 3D/color Data Sets.
}

\author{
S. DRUON, M.-J. ALDON and A. CROSNIER \\ University of Montpellier2-CNRS \\ Laboratoire d'Informatique, de Robotique et de Microélectronique de Montpellier \\ 161 rue Ada \\ 34392 MONTPELLIER - FRANCE
}

\begin{abstract}
In this paper, we address the problem of pair-wise registration of large unstructured $3 D /$ color datasets. Our purpose is to improve the classical ICP (Iterative Closest Point) algorithm by using color information, in order to deal with large datasets and with objects for which the geometric information is not significant enough.

After a brief presentation of classical ICP (Iterative Closest Point) algorithm and of the research works developed to improve its performance, we propose a new strategy to improve the selection of points. Color information is used to reduce the search space during the matching step. Experimental results obtained with real range images show that the algorithm provides an accurate estimation of the rigid transformation.
\end{abstract}

\section{Introduction}

There is an increasing interest in automatic building of 3D computer models of real-world objects and scenes. These models may be used for a large variety of purposes such as building 3D environment maps for robot navigation, creating virtual reality models through observation of real objects, digitizing historical buildings for restoration planning, or archiving heritage objects from museums or cultural organizations.

Building these 3D models requires three steps: the acquisition of a set of range images, the registration of these images in order to place them in a common coordinate system, and a data merge step which simplifies the aligned views to produce a simplified surface description.

Two kinds of techniques may be used for range image acquisition. The first category is based on active range data (time-of-flight, structured light, laser triangulation) and can provide dense range images of the observed scene. In the second category, stereovision and dynamic vision (which uses only one moving camera) are based on video images. They allow us to extract the texture of the scene and a minimum 3D structure (e.g. some interest points), but generally the full geometry of the scene is not available.

Creating an object model requires generally multiple partially overlapping views acquired at different sensor locations. The number of views increases with the sensor resolution. It depends also on the object complexity that create more or less shadow zones, and on the object size. So, these different range images must be registered, i.e. placed in a common coordinate system.

Our research work has been carried out in the context of creation of high-resolution 3D/color models of heritage objects for museums. They include paintings, sculptures, and archaeological figurines, etc. To achieve this, we are developing an integrated approach to the construction of 3D textured models that take full advantage of the complementary nature of range and video data provided by some structured light sensors. Moreover, with this acquisition mode, range and color scanning being achieved by the same sensor, the sampling of color and $3 \mathrm{D}$ data is provided in the same coordinate system (the sensor frame).

In this paper, we address the problem of pair-wise registration of large unstructured $3 \mathrm{D} /$ color datasets. Our purpose is to improve the classical ICP (Iterative Closest Point) algorithm $[1,2]$ by using color information in order to deal with:

- Large datasets (up to a few million points),

- Objects for which geometric information is not significant enough.

This paper is organized as follows. In section 2 we describe the classical ICP (Iterative Closest Point) algorithm and the research works developed to improve its performance. In section 3, we propose a new method to use color information as a constraint in the matching step. The last section presents experimental validation results obtained with real images of three kinds of scanned objects: a colored wood statue, a cylindrical ivory box with colored patterns and an oil painting.

\section{Previous work}

Registration is the process of bringing two data sets into the best possible alignment by estimating the rigid motion 
parameters that transform corresponding data into each other [3]. Data sets to be registered may be intensity pictures, surface data, volume data, or multimodality data (for example textured range images). We present a brief overview of registration methods based on the Iterative Closest Point algorithm applicable to range images of an object taken from different viewpoints.

\subsection{Basic ICP algorithm}

Since its introduction $[1,2]$, ICP has become the most used method for registering $3 \mathrm{D}$ shapes. This algorithm estimates the rigid motion parameters between two 3D shapes by assuming that:

- The two shapes are partially overlapping, i.e. a set of $\mathrm{N}$ points in the first shape are supposed to have correspondences in the second shape,

- They are approximately aligned; i.e. a rough estimate of the initial transformation is known.

The ICP algorithm is composed of two steps: the first one generates temporary correspondences, and the second one estimates the relative rigid-body transformation.

Let us consider two points clouds $\left\{p_{i}\right\}$ (cloud 1) and $\left\{p_{i}^{\prime}\right\}$ (cloud 2) issued from the measurement of an object by a 3D sensor, from two different viewpoints.

From a geometric point of view, we can consider that the corresponding point $p_{i}$ of $p_{i}^{\prime}$, i.e. its closest point in $\left\{p_{i}\right\}$, can be defined as:

$$
p_{i}=\arg \left[\min _{p_{j} \in\left\{p_{i}\right\}}\left\|p_{j}-p^{\prime}{ }_{i}\right\|\right]
$$

For every pair of corresponding points $p_{i}$ and $p_{i}^{\prime}$, we want to find the rotation $(3 \times 3)$ matrix $R$ and the translation $(3 \times 1)$ vector $t$ so that:

$$
p_{i}=R p_{i}^{\prime}+t
$$

with $p=(x, y, z)^{T}$.

For convenience, we use the homogeneous coordinate transformation $T$, which has six free motion parameters ( 3 angles and 3 translation components):

So, we write (2) as:

$$
T(p)=R p+t
$$

$$
p_{i}=T\left(p_{i}^{\prime}\right)
$$

Theoretically, three point pairs $\left(p_{i}, p_{i}^{\prime}\right)$ are necessary to identify a unique transform $T$. However, due to the different noise sources (sensor measurements, image segmentation, point matching), the transformation estimated from three arbitrary point pairs is not generally the best one.

Estimating the best motion parameters requires using an error minimization technique such as searching a leastsquare solution to the over-determined system of equations (4). For a set of $\mathrm{N}$ matches, the criterion to be minimized is:

$$
\varepsilon=\frac{1}{N} \sum_{i=1}^{N}\left\|p_{i}-T p_{i}^{\prime}\right\|^{2}
$$

This two steps procedure must be iterated to reach the convergence of the computed transformation, i. e. when the change in mean square error falls below a threshold, which specifies the required precision of the registration. So, the ICP algorithm can be summarized as follows:

Let $T_{0}$ be an initial estimate of the transformation

Repeat for $k=1 \ldots k_{\max }$, or until termination criteria is met

Find a set of $N_{k}$ closest point pairs in $\left\{p_{i}\right\}$ and $\left\{p_{i}^{\prime}\right\}$, according to (1);

Estimate the transformation $T_{k}$ that minimizes the distance criterion (5)

Apply the transformation $T_{k}$ to all points of $\left\{p_{i}^{\prime}\right\}$.

Besl and Mc Kay [1] have designed this method to register a set of $3 \mathrm{D}$ points $\left\{p_{i}\right\}$ to a reference $3 \mathrm{D}$ model $M$.

Assuming that all the points $p_{i}$ belong to $M$, they have shown that the ICP algorithm always converges monotonically to the nearest local minimum. In our application, cloud $\left\{p_{i}^{\prime}\right\}$ is not a subset of cloud $\left\{p_{i}\right\}$. So, it is necessary to prevent false matching with points that don't belong to the overlapping regions. False matching can occur during the first steps of ICP and lead to a biaised solution.

\subsection{Variants of the ICP algorithm}

Since the last decade, many variants have been introduced to improve the original ICP approach. The reader can find an interesting classification and comparison of these variants in [4]. We give here a brief overview of the major approaches, which try to reduce the cost of the expensive closest point finding, and to make registration more robust against outliers due to noise or to false pairing of nonoverlapping surfaces. 
In [5], all available points are used to achieve the matching phase. In order to decrease the computation time, a reduced set of points may be selected either in one, or in both clouds. For instance, in [5] a random process is used to select different samples of points at each iteration. The closest point research strategy may also be improved by using a k-d tree [7]

Additional viewpoint invariant attributes may be used to select only compatible points during the matching step. They can be computed either from the range image or from additional data provided by the imaging sensor (intensity, color). In [6], a vector of geometric and photometric attributes is attached to each point. It includes the magnitude of the principal curvatures computed from range data, and intensity based attributes (diffuse and reflection coefficients). The photometric data are also exploited in [9] and [10]. Local curvature, texture [8], shape (3D differential attributes) [6] and angle between normals [10] have also been explored.

Different methods have been proposed to eliminate false matches which may prevent the estimation algorithm to converge to the correct solution. In [7], point pairs are eliminated when their distance is larger than a threshold adaptively computed with a statistical method based on the distance distribution. In [5], a Least Median of Square (LMS) estimator classifies range data into inliers and outliers. Moreover, the distance function (5) can be modified in order to reduce the effect of bad matches by including additional terms that measure the points similarity. In [11] a distance in the color space is added to the Euclidian distance.

\subsection{Our approach}

When geometric information is not meaningful enough to achieve registration, color information becomes the only available criterion for the matching step. Our hypothesis states that a colored point should be paired with a point of the same color in most cases. We have seen that one way of applying this constraint is to use a metric taking into account both geometric and color information, as in [11]. The weakness of this approach is to find the correct weights for both terms since they don't have the same nature and don't rely on the same scale. Our approach consists in using a preliminary color-based clustering of the data before performing ICP.

\section{3D matching under color constraints}

In this paper, we present a new approach of the ICP algorithm. The contribution of the work concerns the use of color information to achieve the point selection step. A preliminary classification of the point clouds using color classes aims at

- Improving the robustness of the matching process by only allowing the pairing of color compatible points,

- Reducing the amount of data to be processed,

- Resolving cases of objects for which the alignment problem is difficult to solve with a pure 3D ICP algorithm (symmetries, etc.)

\subsection{Color based classification of the point clouds}

Because light conditions are not controlled during acquisition, we had to choose a perceptual color representation. Furthermore, this representation must be independent of any color calibration since this information is not available on most $3 \mathrm{D}$ commercial sensors.

The segmentation of each data cloud $\left\{p_{i}\right\}$ and $\left\{p_{i}^{\prime}\right\}$ relies on the Hue component of the HSV color space, as defined in [12]. Saturation $S$ and intensity $V$ are not taken into account since they are really dependant on the acquisition conditions. For instance, under normal illumination, most color variations of an object digitalized from different viewpoints come from variations in shading. These variations generally affect the intensity of the points but not their intrinsic color. Moreover, using Hue as additional information for point selection doesn't require an illumination model as in [7] where the intrinsic surface reflectance parameters must be computed.

We consider a color space in which the $H$ component varies from 0 to 6 . With each integer value is associated one pure basic color: Red, Yellow, Green, Cyan, Blue, and Magenta. One color class is characterized by a tight interval centered on one of these values. From each original data cloud, we generate six sub clouds corresponding to each color class. The remaining points are not taken into account.

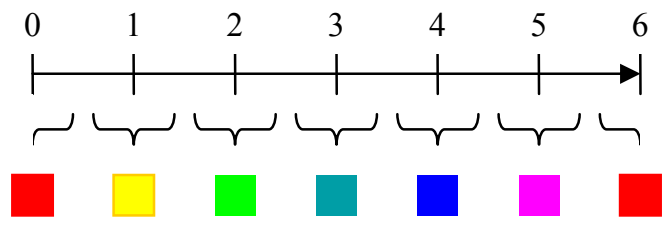

Figure 1: Repartition of the 6 classes on the $H$ component

When saturation is under a certain threshold, a color is more or less grey, and its hue component doesn't seem to 
be meaningful. This is the reason why we also apply a filter on the $S$ component, removing all points with small values of $S$.

\subsection{Criteria for class selection.}

Presently, the registration algorithm uses only $3 \mathrm{D} /$ color points belonging to one class $C$ (for instance to the Red class). We have defined two criteria for the selection of this class:

- The ratio $R_{C}$ of points contained into the class $C$.

A good class must have a reasonable number of points, for example, in the following experimentations we have:

$$
5 \%<R_{C}<15 \%
$$

The lower limit is easy to understand. If a class is less than $5 \%$ of the initial data cloud, we consider that it is a bad representation of the whole population of data. The upper limit is for performance purposes. The aim is to reduce the computation time by trying to select a class which contains regions of interest.

- The ratio $N c$ of points of the class $C$ initially included in the bounding box of data cloud 2

One difficulty with reducing the problem of registration to a sub problem based on only one class is that this class must be representative of the overlapping region. Since we don't have any information about this overlapping region, we use the initial transformation provided by the user in order to estimate this region. The class with the highest number of points in this region is the most likely to allow good registration.

To each class is assigned a score $S c$ based on the following expression:

Where

$$
S c=N c+f(R c)
$$

$$
\begin{aligned}
& \mathrm{f}(R c)=100 \text { if constrain (6) is respected } \\
& \mathrm{f}(R c)=0 \text { if constrain (6) is violated }
\end{aligned}
$$

The class with the highest score $S c$ is selected for the registration.

\subsection{ICP based registration}

For the registration, we now consider only two sub clouds $\left\{\bar{p}_{i}\right\}$ and $\left\{\bar{p}_{i}^{\prime}\right\}$ belonging to the class with the highest value of $\mathrm{Sc}$.

The algorithm for ICP registration makes use of an adaptive threshold Dmax inspired from [7]:

- Let $T_{0}$ be an initial estimate of the transformation

- Initialize Dmax to ( $20 \mathrm{x}$ resolution of the datasets )

- Repeat for $k=1 . . . k_{\max }$,

or until termination criteria is met

- For each point in $\left\{\bar{p}_{i}\right\}$

- Search for its nearest neighbor in $\left\{\bar{p}_{i}{ }_{i}\right\}$.

- If distance $\left(P_{i}, P_{\mathrm{i}}^{\prime}\right)<D \max$

Add the pair to the list of registered pairs $\mathrm{Lk}$

- Compute the mean and standard deviation of the distances from the list $\mathrm{L}_{\mathrm{k}}$

- Set Dmax to ( mean + standard deviation )

- Estimate the transformation $T_{k}$ based on the registered pairs $\mathrm{L}_{\mathrm{k}}$

- Apply the transformation $T_{k}$ to all points of $\left\{\bar{p}_{i}^{\prime}\right\}$.

- Loop until mean, standard deviation, and number of registered pairs are stabilized.

In order to speed up the search process for the closest point, a kd-tree is computed on the cloud $\left\{\bar{p}_{i}{ }_{i}\right\}$ as described in [7]. The complexity of the registration algorithm is :

$$
\mathrm{n}_{1} \cdot \mathrm{n}_{2} \cdot \log \left(\mathrm{n}_{2}\right)
$$

where $\mathrm{n}_{1}$ and $\mathrm{n}_{2}$ are respectively the number of points of $\left\{\bar{p}_{i}\right\}$ and $\left\{\bar{p}_{i}^{\prime}\right\}$.

If $\mathrm{k}_{\max }$ iterations are performed without convergence, a new registration is performed with the class having the second highest score, and so on . 


\section{Experimental results with real data}

This algorithm has been evaluated with data from real objects acquisitions. The datasets described here were acquired with a Breuckman TRITOS sensor [14] (Image:1280x1024 pixels). This sensor uses a non-contact 3D measuring method (fringe projection technique) with color capabilities, each RGB color component being coded on 5 bits.

\subsection{Description of the data sets}

Three sets of data are considered in this paper. They have been selected because they are representative of different object classes encountered in the domain of art preservation.

\begin{tabular}{|c|c|c|c|}
\hline $\begin{array}{l}\text { Name of the } \\
\text { dataset : }\end{array}$ & $\begin{array}{c}\text { Bali } \\
\text { ( fig } 4 \text { ) }\end{array}$ & $\begin{array}{l}\text { Ivoire } \\
\text { ( fig } 5 \text { ) }\end{array}$ & $\begin{array}{l}\text { Wallis } \\
\text { ( fig } 6 \text { ) }\end{array}$ \\
\hline Nature & $\begin{array}{c}\text { Painted } \\
\text { wooden } \\
\text { statue }\end{array}$ & $\begin{array}{l}\text { Colored } \\
\text { Ivory Box }\end{array}$ & $\begin{array}{c}\text { Oil } \\
\text { Painting }\end{array}$ \\
\hline $\begin{array}{c}\text { Size of cloud } \\
1\end{array}$ & $\begin{array}{c}209628 \\
\text { points }\end{array}$ & $\begin{array}{c}312950 \\
\text { points }\end{array}$ & $\begin{array}{c}1030658 \\
\text { points }\end{array}$ \\
\hline $\begin{array}{c}\text { Size of cloud } \\
2 \\
\end{array}$ & $\begin{array}{c}247461 \\
\text { points }\end{array}$ & $\begin{array}{c}306978 \\
\text { points }\end{array}$ & $\begin{array}{c}1036735 \\
\text { Points }\end{array}$ \\
\hline $\begin{array}{c}\text { Sensor } \\
\text { Resolution } \\
(\mu \mathrm{m}) \\
\text { X Y Z }\end{array}$ & $180 \times 180 \times 6$ & $60 \times 60 \times 3$ & $60 \times 60 \times 3$ \\
\hline $\begin{array}{c}3 \mathrm{D} \\
\text { Information }\end{array}$ & Rich & $\begin{array}{c}\text { Poor } \\
\text { (cylinder) }\end{array}$ & $\begin{array}{c}\text { Poor } \\
\text { (plane) }\end{array}$ \\
\hline $\begin{array}{c}\text { Color } \\
\text { information }\end{array}$ & $\begin{array}{c}\text { Poor } \\
\text { (shiny) }\end{array}$ & Rich & Rich \\
\hline
\end{tabular}

Table 1 : Datasets description

Due to the limited size of this paper, the effect of sensor errors and noise is not investigated here by using synthetic images. However, we underline that results presented in the following section have been obtained with real noisy data:

- Noise on color data is essentially due to the digitalization process (each color component is encoded with only 5 bits), and to the acquisition conditions (lighting variations)

- Concerning the range data quality, Bali has a 3D complex shape, which involves many shadow zones, Ivoire and Wallis are difficult objects because their shape present symmetries and any interest point.

\subsection{Results}

The results obtained with our registration algorithm on these 3 datasets are summarized in table 2 .

For each experiment, we give the number of points in the selected color class for each cloud, the final average error in $\mathrm{mm}$, the number of iterations required to fulfill the convergence criteria, and the final number of pairs in $\mathrm{L}_{\mathrm{k}}$.

We consider that convergence is reached when the two following conditions are satisfied during two successive steps of the ICP algorithm :

- The number of pairs remains the same,

- The average error and the standard deviation variations are less then 1e-6 mm

\begin{tabular}{|c|c|c|c|}
\hline $\begin{array}{c}\text { Name of the } \\
\text { dataset : }\end{array}$ & Bali & Ivoire & Wallis \\
\hline Selected Class & Red & Green & Cyan \\
\hline $\begin{array}{c}\text { Ratio of } \\
\text { selected points }\end{array}$ & $5.95 \%$ & $7.06 \%$ & $9.10 \%$ \\
\hline $\begin{array}{c}\text { Final average } \\
\text { error (mm) }\end{array}$ & 0.289311 & 0.06311 & 0.140817 \\
\hline Iterations & 58 & 102 & 201 \\
\hline $\begin{array}{c}\text { Final number } \\
\text { of pairs in } L_{k}\end{array}$ & 5677 & 11419 & 40473 \\
\hline
\end{tabular}

Table 2: Summary of the results

The final average error is very close to the sensor resolution chosen for each experiment, which validates the quality of the final registration.

Running on a Dell Pentium 4 - $2.9 \mathrm{GHz}$ - 1 Gig Ram computer, without any optimization of the source code, the experiments took a few minutes for Ivoire and Bali. In the case of Wallis the computing time is very important. Because of the poor $3 \mathrm{D}$ information in the $\mathrm{Z}$ direction., the kd-tree structure degenerates. Furthermore, the class selection could be enhanced.

We present in figure 2, the curves showing the evolution of mean and standard deviation of distances resulting from registration for Bali experimentation. 


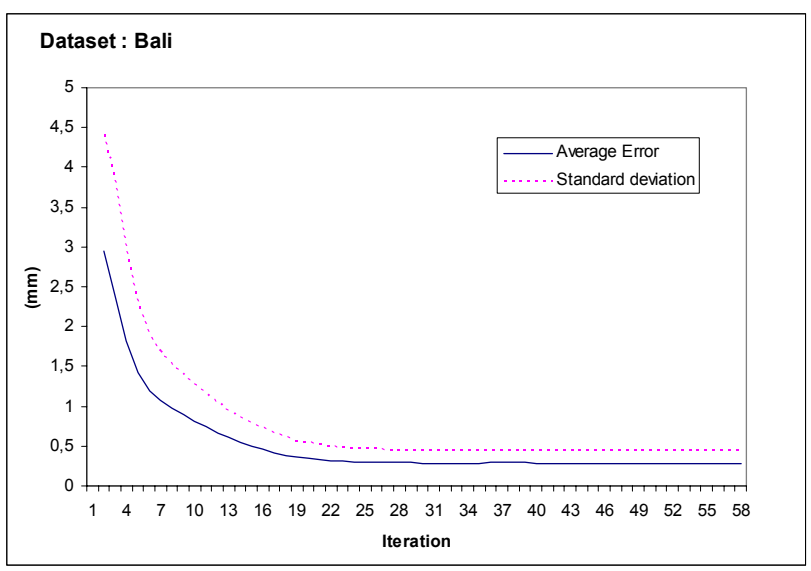

Figure 2 : Evolution of error in Bali experiment

Figure 3 shows the evolution of registration through the number of pairs in Lk.

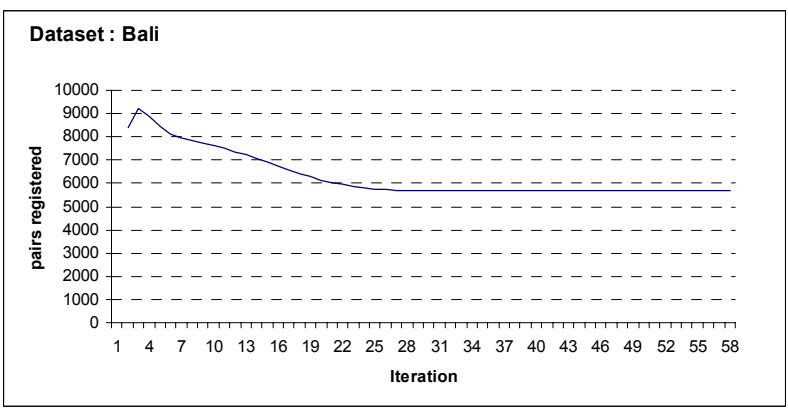

Figure 3

We can deduce from those results that rough registration is reached after only 25-30 iterations. 3D views of original datasets before and after registration are illustrated on figures 4, 5, 6 and 7. We can outline that, in the case of Ivoire and Wallis, purely geometric registration algorithms do not converge to an acceptable solution.

\section{Conclusions}

We have proposed a new variant of the ICP algorithm that may be efficiently applied to large $3 \mathrm{D} /$ color point sets by taking advantage of the color information. A preliminary segmentation step is used to select only points belonging to an interesting color class, in order to speed up the 3D matching and to increase the convergence rate of the iterative process The experimental validation achieved with real data shows that:

- The computational cost of the algorithm is reduced.

- The method provides an accurate estimation of the rigid transformation, even in the case of objects for which the alignment problem is difficult to solve with a pure 3D ICP algorithm.

This solution appears as a new alternative for $3 \mathrm{D}$ color objects when purely geometric registration does not lead to an acceptable solution.

Our present work aims at improving the segmentation process by introducing automatic clustering in the process of class building. Moreover, further work must be done on the computation time, by introducing parallelism.

Next step on this work concerns experimental validation of the method by comparing it with other approaches, whenever possible.

\section{References}

[1] P. Besl and N.D McKay, "A Method for Registration of 3-D Shapes", Proc. of IEEE Transactions on Pattern Analysis and Machine Intelligence, Vol. 14, No. 2, pp.239-256, 1992

[2] Y. Chen and G.Medioni, "Object Modelling by Registration of Multiple Range Images", Image and Vision Computing, Vol. 10, no. 3, 1992, pp. 145-155.

[3] S. Seeger, X. Laboureux, " Feature Extraction and Registration”, Principles of 3D Image Analysis and Synthesis, Kluwer Academic Pub, 2000, pp. 153-166.

[4] Szymon Rusinkiewicz and Mark Levoy, "Efficient Variant of the ICP Algorithm". Proc. 3DIM, Québec, Canada, May 28- June 1, 2001, pp. 145-152.

[5] G. Blais and M. D. Levine, "Registrating Multi-View Range Data to Create 3-D Computer Objects", IEEE Transactions on Pattern Analysis and Machine Intelligence, Vol. 17, No. 8, 1995, pp.820-824.

[6] Takeshi Masuda and Naokazu Yokoya, "A Robust Method for Registration and Segmentation of Multiple Range Images", Computer Vision And Image Understanding, Vol. 61, No. 3, May 1995, pp. 295-307.

[7] G. Godin, D. Laurendeau, R. Bergevin, " A method for the registration of Attributed Range Images", Proc. 3DIM, Québec, Canada, May 28- June 1, 2001, pp. 179-186.

[8] Zhengyou Zhang, "Iterative Point Matching for Registration of Free Form Curves", IJCV, vol. 13, no. 2, 1994, pp 119152.

[9] Weik S., "Registration of 3D partial surface models using luminance and depth information", Proc. 3DIM, Ottawa, Canada, May 1997, pp. 93-100.

[10] Kari Pulli, "Multiview Registration for Large Data Sets", Proc. 3DIM, Ottawa, Canada, October 1999, pp. 160-168.

[11] Andrew Johnson and Sing Bing Kang, "Registration and Integration of Textured 3-D Data", Proc. 3DIM, Ottawa, Canada, May 1997, pp. 234-241.

[12] Foley and Van Dam, "Fundamentals of interactive computer graphics", 1982.

[13] Breuckmann web site on Tritos sensor http://www.breuckmann.com/HTML/engl/tritos.html 

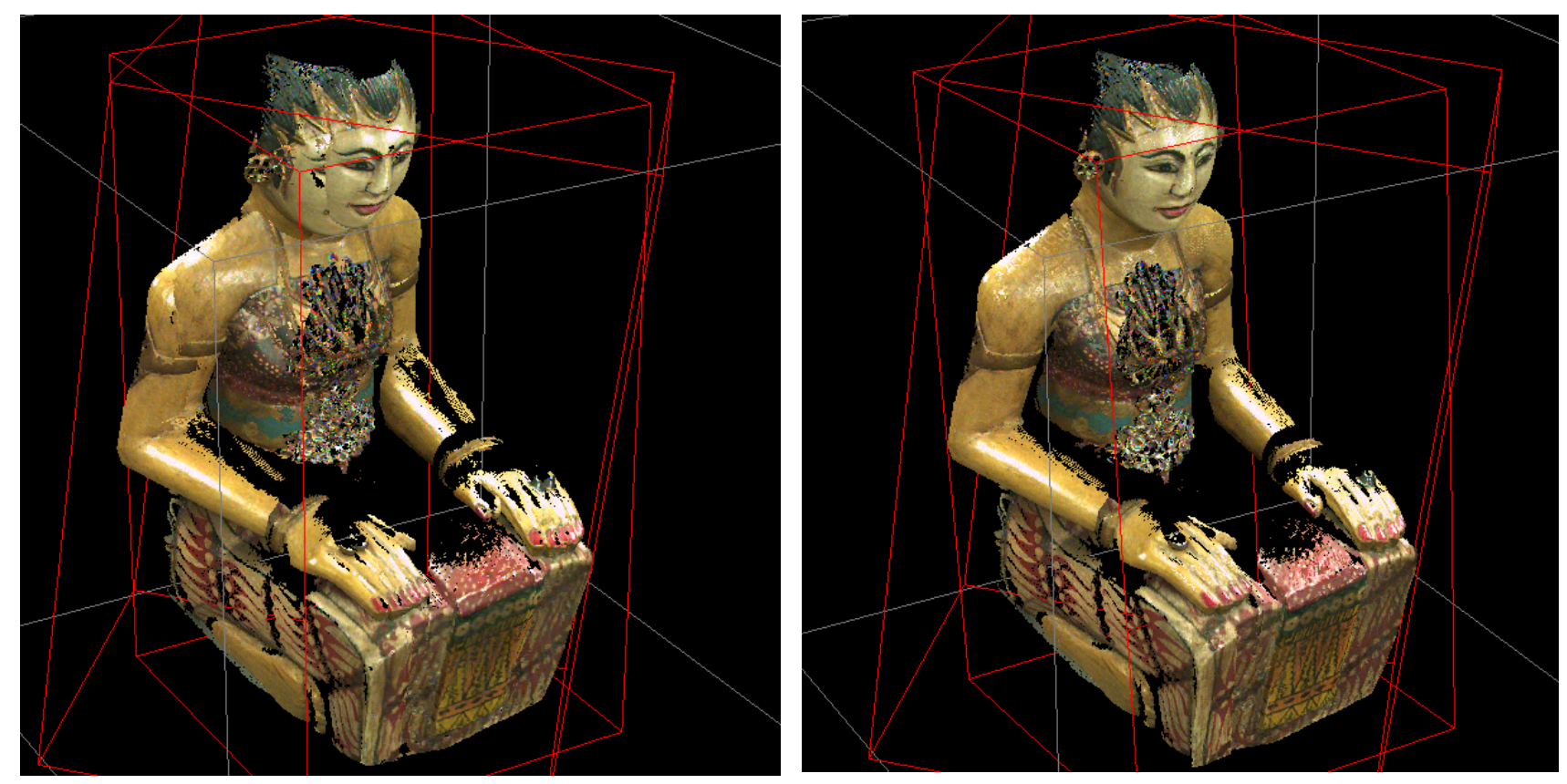

Figure 4 : Bali before and after registration
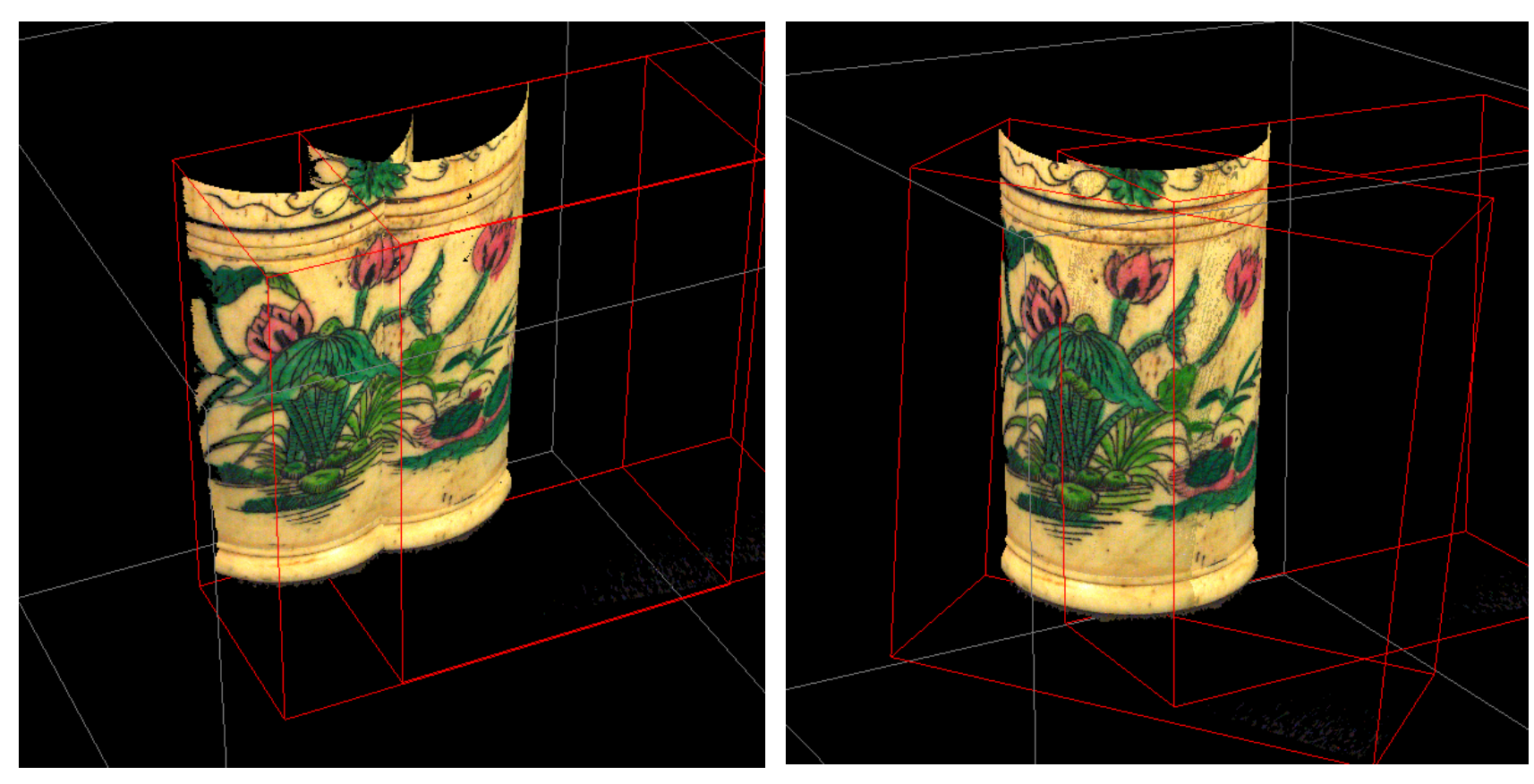

Figure 5 : Ivoire before and after registration 

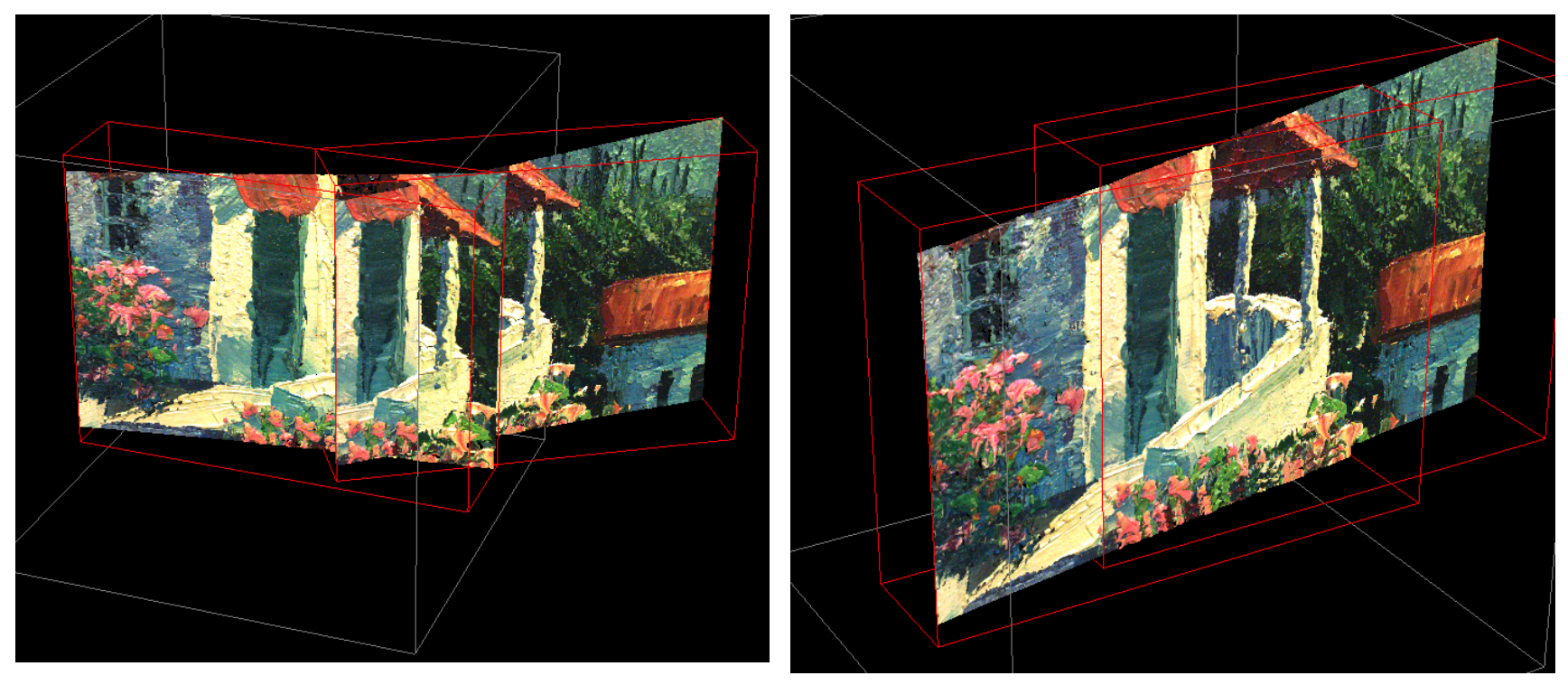

Figure 6: Wallis before and after registration

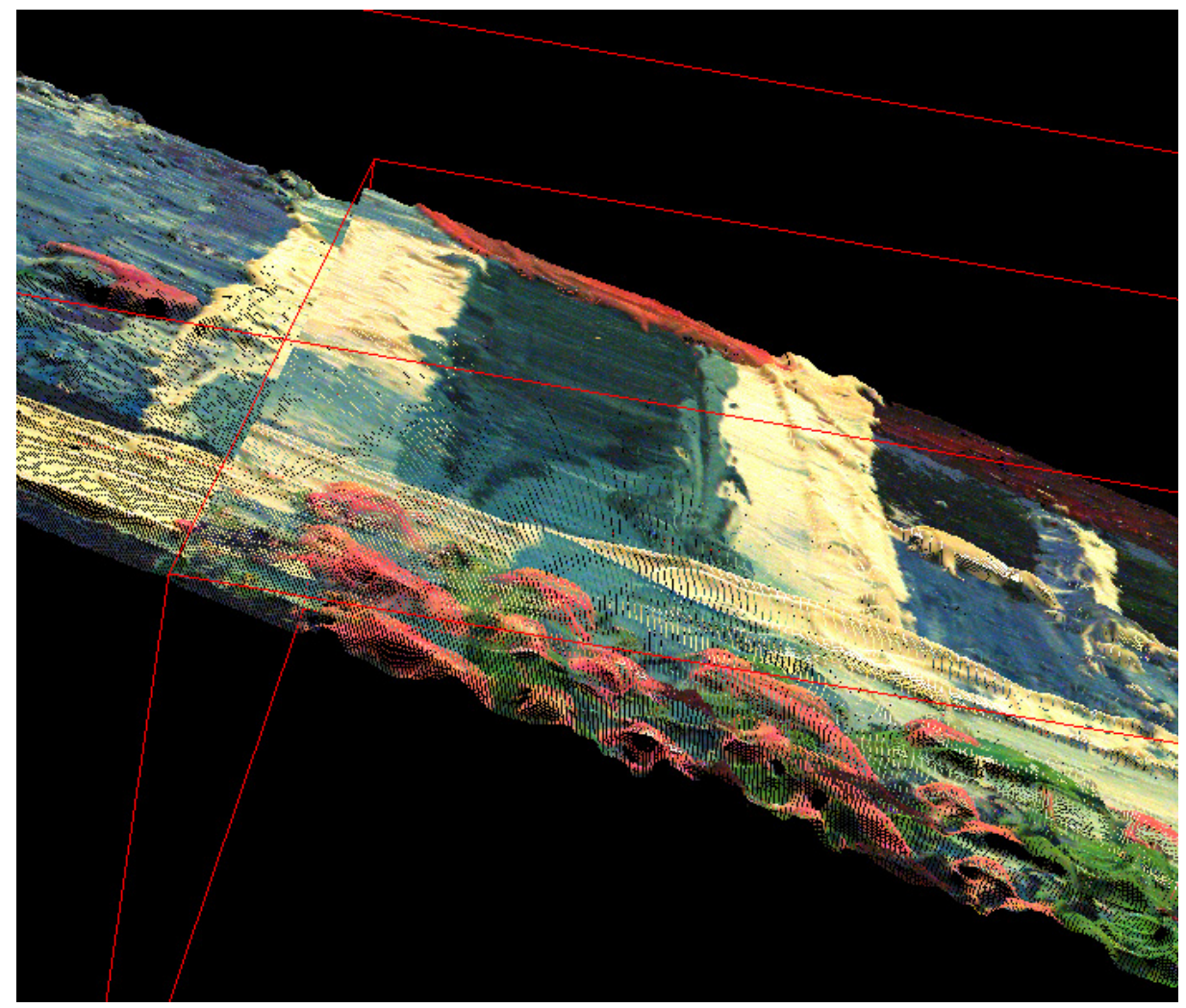

Figure 7: Closer view of the surface of Wallis after registration 